\title{
Performance of elevated water tank staging with base isolation under blast loading
}

\author{
Boda Balaraju' ${ }^{1}$, Atulkumar Manchalwar ${ }^{2}$
}

${ }^{1} \mathrm{M}$. Tech Scholar, Gokaraju Rangaraju Institute of Engineering and Technology, Hyderabad, India

${ }^{2}$ Associate Professor, Gokaraju Rangaraju Institute of Engineering and Technology, Hyderabad, India

\begin{abstract}
In this present study aims to evaluate the performance of base isolation device under different intensity blast induced ground excitations for an elevated water tank staging. In this study mainly focused to improve the performance of the base isolator and minimize the damage of the structure. To know the performance of base isolator two models are considered one is fixed base model and another one is supported with base isolator model for both non-linear time history analysis is carried out with the help of SAP 2000 software subjected to four different underground blast intensities. From the analysis, it is observed that by using base isolator supported model structural responsive parameters such as base shear, top storey accelerations are efficiently reduced when compared to the fixed base structure. Hence it is proved that adopting base isolation technique we considerably reduce the damage of the structure subjected to underground blast vibrations.
\end{abstract}

\section{Introduction}

Underground blast is a one type of dynamic loading which is similar to the earthquake but with a different frequency is acting over a short duration with high intensity and due to shaking of ground it releases some amount of energy in the form of waves.

According to location of water tank, generally water storing tank are classifying as elevated water tank, ground support and underground water tank. Elevated water tanks are basic important structures for storing and distribution of water by using gravity effect. Generally elevated water tank supporting system constructed either shaft type or frame type staging. Frame supported type staging showing better performance subjected to lateral loads such as earthquake or blast loads.

In post-blast phase many structures are damaged due to dynamic behavior of loading and structure experiences nonlinear inelastic behavior. To reduce the damage of the structure various researchers are introducing several base isolation and damping techniques. In this present base isolation concept is adopted to decrease the responsive parameters of the structure.

In recent times, many authors are worked on the base isolation systems W. Shenton [1] worked on the seismic by using x-plate metallic damper and found that by using $\mathrm{x}$-plate damper the seismic performance of the structure is improved. response of water tank using base isolation and found that by using base isolation technique responsive parameters of the structure efficiently reduced compared to the fixed base structure. Seleemah [2] studied the performance of the elevated liquid storage tanks by using elastomeric or sliding bearing isolators. Sorace [3] conducted a study on the retrofitting of water tank with base isolation strategy for shaft staging type structure. Atulkumar Manchalwar [4] worked on the vibration control of the structure by using tuned mass damper as base isolator. Omprakash Reddy [5] researched on the performance of base isolated structure under blast loading. Jyothi Sravya [6] studied the performance of U-shaped isolator and compare with soil structure interaction and observed that soil interaction provides considerable flexibility to the structure. Manchalwar and Bakre [7] studied on the U-shaped metallic damper as an isolator with isolated foundation and concludes that structural damages are significantly reduced in both the isolation techniques. Manchalwar and Bakre [8] investigated on RC structured frame equipped with aluminum and steel x-plate damper. Nirmala and Manchalwar [9] conducted a study on the water tank 


\section{Blast induced a cceleration values calculation: -}

The researchers Hinman [10], Carvalho and battista [11] are proposed the blast induced ground acceleration equation in the form of an exponential decaying function which is given below.

$$
\ddot{x}_{g}(t)=-\frac{1}{t_{d}} v e^{\frac{-t}{t_{d}}}
$$

In the above equation kumar [12] proposed the peak particle velocity $(v)$ in the form of empirical equation, $t_{d}$ is the wave arrival time which is calculated by using $t_{d}=R / C$ where $\mathrm{R}$ is the distance from the source of blast to structure for this study is taken by $100 \mathrm{~m}$ and $\mathrm{C}$ is propagation velocity of blast wave. $\ddot{x}_{g}(t)$ is the ground acceleration.

$$
\mathrm{V}=\frac{f^{0.642} S D^{-1.463}}{\gamma_{D}}
$$

where $\gamma_{D}$ is the average unit weight of granite rock deposit (26500 kg per one metre cube), $\mathrm{f}$ is the uni-axial compressive strength of granite deposit and SD is the scaled distance which is calculated by ratio of charge point distance to square root of the blast charge weight $(10,25,50,75$ tons $)$. $\mathrm{E}$ is the modulus of elasticity of granite deposit $73.9 \mathrm{GPa}$.

\section{Problem statement}

To examine the blast performance of the elevated water tank structure by using lead rubber bearing 12 column $24 \mathrm{~m}$ height staging is considered, plan and elevation which is taken from the Lakhade [13] shown in fig $1 \& 2$. Modelling and non-linear time history analysis of structure is conducted in SAP 2000 software. for this study M20 and Fe 500 reinforced steel is used, for design of structure dead loads and live loads are taken from the IS $875-1983$ part 1 and part 2 .

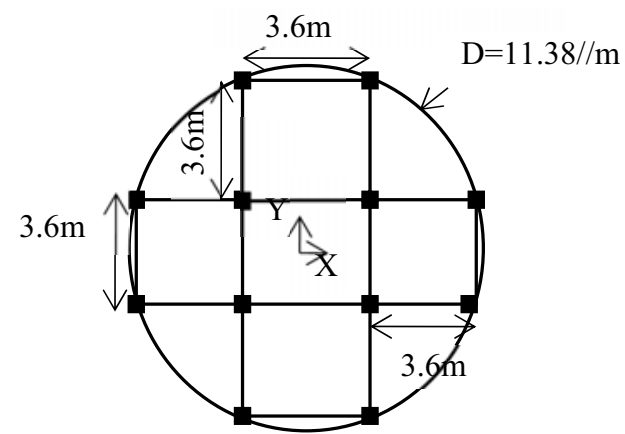

Fig 1. plan view of the water tank columns

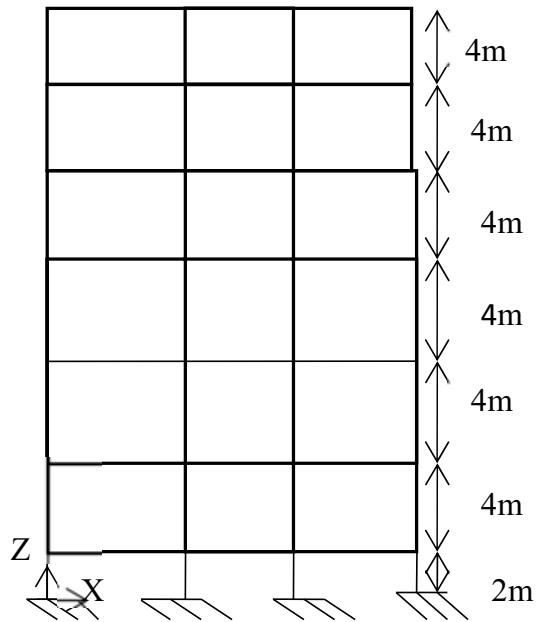

Fig.2. Elevation view of water tank staging

Table 1. Dimensions of water tank staging

\begin{tabular}{|c|c|c|c|c|}
\hline $\begin{array}{c}\text { Capacity } \\
\text { of the } \\
\text { tank } \\
(\mathrm{ML})\end{array}$ & $\begin{array}{c}\text { Diameter } \\
\text { of the } \\
\text { tank }(\mathrm{m})\end{array}$ & $\begin{array}{c}\text { Column } \\
\text { size } \\
(\mathrm{mm})\end{array}$ & $\begin{array}{c}\text { Bottom } \\
\text { beam } \\
\text { size } \\
(\mathrm{mm})\end{array}$ & $\begin{array}{c}\text { Brace } \\
\text { beam } \\
\text { size } \\
(\mathrm{mm})\end{array}$ \\
\hline 0.6 & 11.38 & $\begin{array}{c}400 \mathrm{x} \\
400\end{array}$ & $\begin{array}{c}350 \mathrm{x} \\
750\end{array}$ & $\begin{array}{c}300 \mathrm{x} \\
550\end{array}$ \\
\hline
\end{tabular}

\section{Dynamic response of the structure}

To determine the performance of lead rubber bearing isolator nonlinear time history analysis is conducted. For this study the LRB parameters such as time period $\left(\mathrm{T}_{\mathrm{b}}\right)$ is taken as 2 seconds. initial stiffness is calculated from $\mathrm{T}_{\mathrm{b}}=2 \pi \sqrt{\frac{M}{K}}$ for inner columns and outer columns it is $1158.8 \mathrm{kN} / \mathrm{m} \& 795.1 \mathrm{kN} / \mathrm{m}$ respectively. Post yield stiffness ratio $(\alpha)$ is taken as 0.1 , yield strength $(\mathrm{Q})$ of isolator is calculated from $\frac{Q}{W}$ ratio which is 0.05 , where $\mathrm{W}$ is the structure weight from the calculations yield strength of inner and outer columns is $57.59 \mathrm{kN} \& 39.51 \mathrm{kN}$ respectively.

\subsection{Base shear comparison}

To estimate the performance of base isolator, nonlinear time history analysis is conducted and plotted the graph between base shear and time. From the graphs observed that base shear values effectively reduced shown in fig.3. 

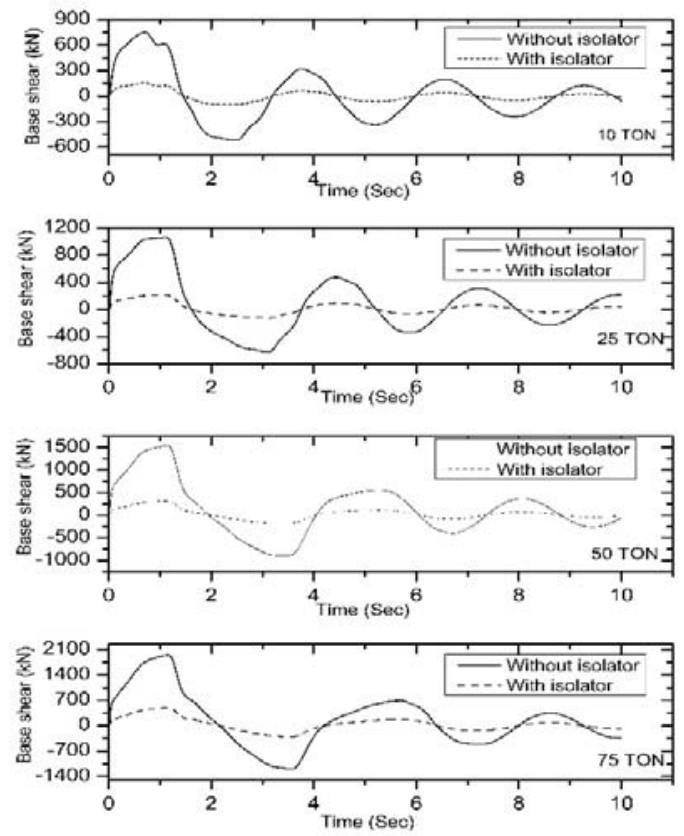

Fig.3. Base shear versus time graph

\subsection{Acceleration comparison}

To examine the performance of the base isolation, nonlinear time history analysis is performed under four different blast intensities. The graphs are plotted between the top story acceleration and time for different blast loads shown in fig.4. From the graphs observed that, the top story accelerations are considerably decreased in the case of base isolation when compared to the without base isolation case.
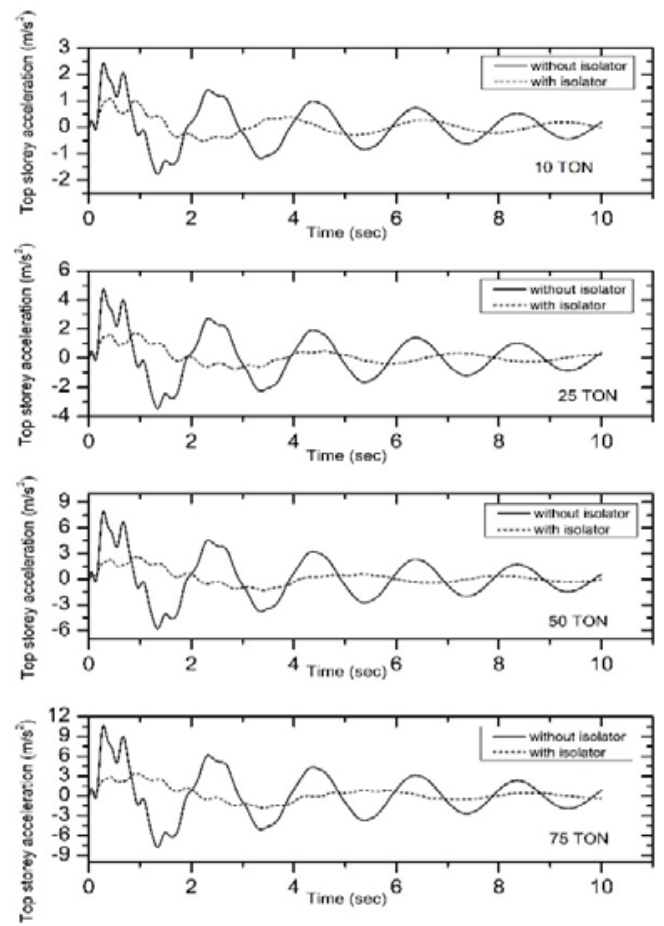

Fig.4. acceleration versus time graph

\subsection{Hysteresis loop}

When the underground blast takes place higher amount of energy is released in different forms, this energy is responsible for the structural damage. By using base isolation technique, we can considerably dissipate the energy. Hysteresis loop is plotted between force $(\mathrm{kN})$ and deformation $(\mathrm{m})$ shown in fig. 5 .
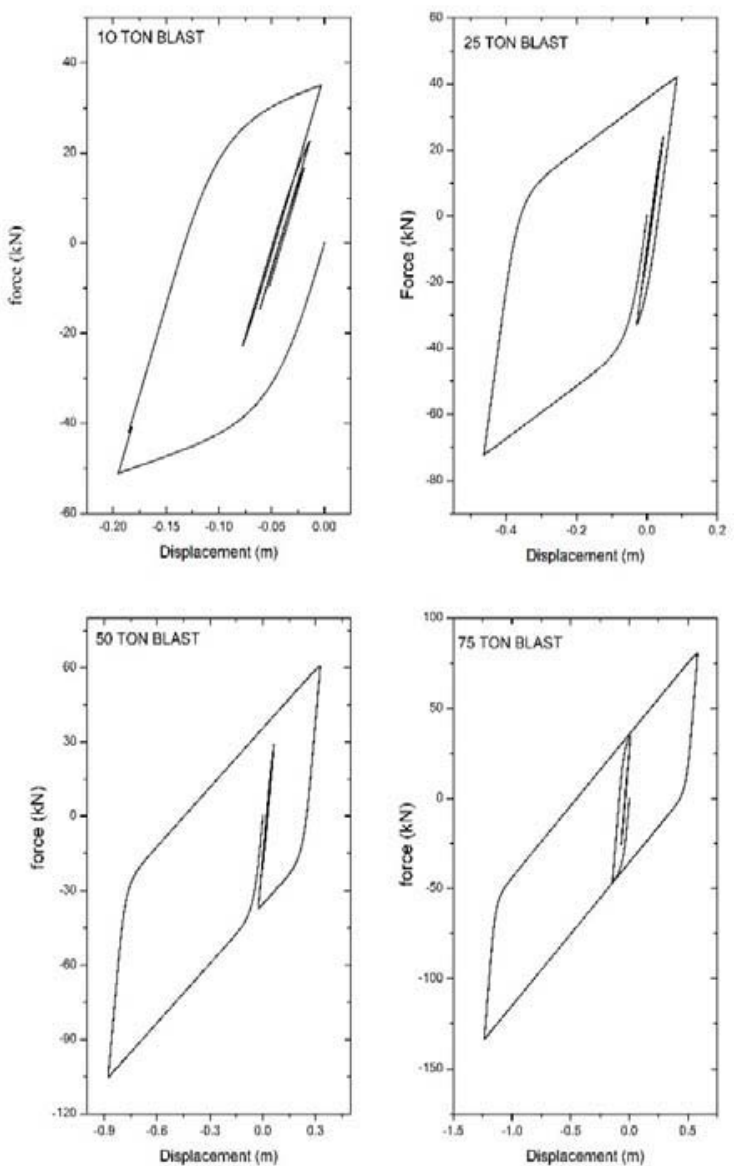

Fig.5. force versus displacement graph

\section{Conclusion}

In the present study, 12 column $24 \mathrm{~m}$ staging is considered and it is supported with passive control device i.e., Lead rubber bearing subjected to different intensity blast loading. The blast is derived as exponential decaying function in the form of ground accelerations. For this study nonlinear time history analysis is conducted in SAP 2000 software to know the behavior of the base isolator. From the results, observed that by using of base isolator top story acceleration of the structure are significantly reduced. The base shear values and energy dissipation is considerably decreasing and improving the structural performance. From the study decided to the base isolation concept is very effective to reduce the blast parameters and minimize the damage of the structure. 


\section{References}

1. Shenton, Harry W., and Francis P. Hampton. Journal of Structural Engineering 125.9 (1999): 965-976.

2. Seleemah, Ayman A., and Mohamed ElSharkawy. Earthquake and Structures 2.4 (2011): 397-412.

3. Sorace, S., G. Terenzi, and I. Costoli. International Journal of Civil Engineering and Technology 9 (2018): 891-902.

4. Manchalwar, Atulkumar, and S. V. Bakre. " International Journal of Dynamics and Control (2020): 1-10.

5. Reddy, N. Omprakash, and A. Manchalwar. E3S Web of Conferences. Vol. 184. EDP Sciences, 2020.

6. Kotkunde, N., Krishna, G., Shenoy, S.K., Gupta, A.K., Singh, S.K. International Journal of Material Forming, 10 (2), pp. 255-266 (2017)
7. Govardhan, D., Kumar, A.C.S., Murti, K.G.K., Madhusudhan Reddy, G. Materials and Design, 36, pp. 206-214. (2012)

8. Kumar, P., Singhal, A., Mehta, S., Mittal, A. Journal of Real-Time Image Processing, 11 (1), pp. 93-109. (2016)

9. Raghunadha Reddy, T., Vishnu Vardhan, B., Vijayapal Reddy, P. International Journal of Applied Engineering Research, 11 (5), pp. 30923102 (2016)

10. Hussaini, S.M., Krishna, G., Gupta, A.K., Singh, S.K. Journal of Manufacturing Processes, 18, pp. 151-158 (2015) 